\title{
Identificação e variabilidade genética de isolados de Colletotrichum causando antracnose em inflorescências de plantas ornamentais tropicais
}

\author{
Identification and genetic variability of Colletotrichum isolates causing anthracnose in inflorescence \\ of ornamental tropical plants
}

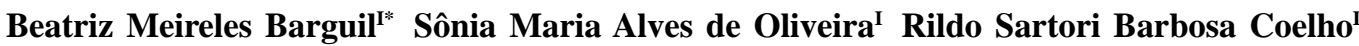 \\ José Evando Aguiar Beserra JúniorII
}

RESUMO

A antracnose afeta a qualidade de inflorescências de plantas ornamentais tropicais, e a espécie fúngica Colletotrichum gloeosporioides tem sido relacionada a essa doença apenas por análises morfológicas. Por isso, o presente trabalho teve como objetivos identificar isolados de Colletotrichum coletados em plantas de antúrio (Anthurium andraeanum), bastão do imperador (Etlingera elatior) $e$ helicônia (Heliconia spp.), por meio de caracteres morfológicos e reação em cadeia da polimerase (PCR), e avaliar a variabilidade genética por meio de oligonucleotídeos arbitrários (AP-PCR). Pelas características morfológicas de tamanho de conídio e de apressório, todos os isolados foram identificados como C. gloeosporioides. Um fragmento de 450pb específico para C. gloeosporioides foi amplificado em todos os isolados analisados, com exceção de C 23 e C 35. A caracterização molecular realizada com três oligonucleotídeos arbitrários ((GACAC), (GACA) e (CAG) $)_{5}$ ) possibilitou a formação de três grupos de isolados, com padrões de bandas distintos. Portanto, conclui-se que as metodologias utilizadas foram eficientes na identificação de isolados de $\mathbf{C}$. gloeosporioides provenientes das espécies ornamentais avaliadas e que, nos isolados analisados, não existe relação entre a similaridade observada no padrão de bandas obtido por AP-PCR e a área de coleta ou a planta hospedeira.

Palavras-chave: Anthurium andraeanum, $A P-P C R$, Etlingera elatior, Heliconia spp., ITS.

\section{ABSTRACT}

Anthracnose affects inflorescences quality of ornamentals tropical plants and the fungi specie Colletotrichum gloeosporioides has been related with this disease based only on morphology. Therefore, the objectives of this research was to identify Colletotrichum isolates collected on anthurium (Anthurium andraeanum), torch ginger (Etlingera elatior) and heliconia (Heliconia spp.) plants by means of morphology and polymerase chain reaction (PCR) and also verify the genetic variability using arbitrary-primed PCR (AP-PCR). All isolates were identified as $C$. gloeosporioides by conidium and appressorium size. A fragment of $450 \mathrm{bp}$ specific for $\boldsymbol{C}$. gloeosporioides was amplified for all isolates analyzed, except for $C 23$ and $C 35$ isolates. The molecular characterization yielded three groups of isolates with different band patterns by using $(G A C A C)_{3},(G A C A)_{4}$ and $(C A G)_{5} A P-P C R$. The employed methodologies were efficient to identify the $C$. gloeosporioides isolates collected on ornamental plants and there isn't relation between similarity of band patterns and geographic region or plant specie on the isolates analyzed.

Key words: Anthurium andraeanum, $A P-P C R$, Etlingera elatior, Heliconia spp., ITS.

\section{INTRODUÇÃO}

A floricultura tropical é uma atividade em ascensão no Brasil, uma vez que as flores tropicais apresentam características, tais como durabilidade, beleza e diversidade de cores e formatos, que propiciam grande aceitação pelo mercado consumidor e elevado potencial de crescimento no mercado nacional e internacional (LOGES et al., 2005).

As condições predominantes de temperatura e umidade relativa são bastante favoráveis para o cultivo das diversas espécies de plantas tropicais durante o ano todo na região Nordeste do Brasil (WARUMBY et al., 2004). Essas condições também propiciam a ocorrência de doenças fúngicas, as quais

IDepartamento de Agronomia, Setor de Fitossanidade, Universidade Federal Rural de Pernambuco (UFRPE), 52171-900, Recife, PE, Brasil. E-mail: beatriz_barguil@hotmail.com. *Autor para correspondência.

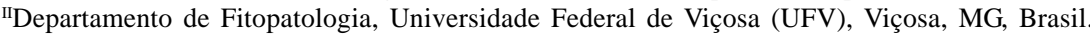


podem afetar inflorescências, flores, folhas, pseudocaules, rizomas e raízes, tornando-se mais severas sob condições de estresse hídrico ou nutricional do hospedeiro (WARUMBY et al., 2004). No Brasil, a antracnose destaca-se das demais doenças fúngicas em plantas ornamentais por afetar várias espécies de importância comercial, como Anthurium andraeanum (PITTA et al., 1990), Etlingera elatior, Tapeinochilos ananassae, Heliconia stricta, $\mathrm{H}$. psittacorum x H. sphathocircinata cultivar 'Golden Torch', H. bihai (LINS \& COELHO, 2004), H. chartacea cultivar 'Sex Pink' (BARGUIL et al., 2005) e Calathea burle-max (ALMEIDA et al., 2006). Segundo esses autores, a espécie isolada foi Colletotrichum gloeosporioides, que foi identificada por meio de características morfológicas.

Marcadores moleculares, como AFLP e APPCR, vêm sendo utilizados para identificação e observação de variabilidade genética de isolados de Colletotrichum provenientes de diversas fruteiras (FREEMAN \& SHABI, 1996; PERES et al., 2002; XIAO et al., 2004; TALHINHAS et al., 2005), de feijoeiro (Phaseolus vulgaris) (SICARD et al., 1997) e lupino ornamental (Lupinus spp.) (TALHINHAS et al., 2002), dentre outras espécies. Embora a antracnose possa comprometer a qualidade na produção de plantas ornamentais tropicais na região Nordeste do Brasil, nenhum estudo sobre a variabilidade genética de isolados de Colletotrichum provenientes dessas culturas foi realizado.

Portanto, o presente trabalho teve como objetivos identificar isolados de Colletotrichum coletados em antúrio (A. andraeanum), bastão do imperador (E. elatior) e em helicônia (Heliconia spp.), utilizando caracteres morfológicos e técnica da reação em cadeia da polimerase (PCR) com oligonucleotídeos específicos, e, estudar a variabilidade genética por meio de oligonucleotídeos arbitrários (AP-PCR).

\section{MATERIAL E MÉTODOS}

Os isolados de Colletotrichum foram obtidos de lesões em brácteas de inflorescências de antúrio (Anthurium spp.), bastão do imperador ( $\boldsymbol{E}$. elatior) e helicônia (Heliconia spp.) provenientes de municípios dos Estados de Pernambuco, Ceará e Paraíba, entre os meses de fevereiro e outubro de 2005 (Tabela 1). O material coletado foi encaminhado ao laboratório, onde os fragmentos de tecido provenientes de lesões nas brácteas foram tratados com hipoclorito de sódio (1,5\%). Em seguida, foram lavados duas vezes em água destilada esterilizada (ADE) e colocados em placas de Petri contendo meio de cultura batata- dextrose-ágar (BDA). Para cada isolado, foram obtidas culturas puras por meio de cultivo monospórico, sendo a seguir repicados para tubo de ensaio contendo meio BDA e mantidos a $4^{\circ} \mathrm{C}$. Os isolados foram depositados na Coleção de Culturas de Fungos Fitopatogênicos da Universidade Federal Rural de Pernambuco (UFRPE).

A avaliação morfológica foi realizada com base no tamanho dos conídios e apressórios, empregando-se a técnica da microcultura (MENEZES \& ASSIS, 2004). As culturas foram mantidas sob alternância luminosa de 12 horas e temperatura de $25^{\circ} \mathrm{C}$ durante sete dias. Após esse período, as lamínulas foram removidas, coradas com azul de Amann e observadas em microscópio de luz. Cada isolado foi avaliado por meio da medição do comprimento e da largura de 50 conídios e apressórios.

Os 35 isolados de Colletotrichum obtidos de plantas ornamentais foram cultivados em meio BDA a $25^{\circ} \mathrm{C}$, com fotoperíodo de 12 horas. Também foi cultivado um isolado de $\boldsymbol{C}$. acutatum coletado em cajueiro (Anacardium occidentale), proveniente do município de Pacajús, Estado do Ceará, e cedido pela Embrapa-CNPAT. Após sete dias, cerca de 50mg de micélio aéreo do fungo foram transferidos assepticamente para microtubos de $1,5 \mathrm{~mL}$ e imediatamente congelados em $\mathrm{N}_{2}$ líquido. O DNA genômico foi extraído pelo protocolo CTAB (cationic hexadecyl trimethyl ammonium bromide), segundo FERREIRA\& GRATTAPAGLIA(1998). Aconcentração de DNA nas amostras foi estimada em gel de agarose 0,8\% corado com brometo de etídeo.

Foram utilizados os oligonucleotídeos CaInt2 (5'-GGGGAAGCCTCTCGCGG-3'), específico para $\boldsymbol{C}$. acutatum ou CgInt (5'-GGCCTCCCGCCTCCGGGCGG3'), específico para $\boldsymbol{C}$. gloeosporioides, em conjunto com o oligonucleotídeo ITS4, para diagnóstico utilizando PCR, para amplificação da região ITS do DNA ribossômico dos isolados analisados. As PCRs foram realizadas em volume total de $25 \mu \mathrm{L}$, contendo $2,5 \mu \mathrm{L}$ de tampão 10X (KCl 100mM; Tris-HCl 100mM pH 9,0; Triton-X 1\%), 2,0 $\mu \mathrm{L}$ de dNTPs 2,5mM, 2,0 $\mu \mathrm{L}$ de $\mathrm{MgCl}_{2}$ $25 \mathrm{mM}, 1 \mu \mathrm{L}$ de cada oligonucleotídeo $40 \mu \mathrm{M}, 1 \mathrm{U}$ da DNA 2 Taq Polimerase, $1 \mu \mathrm{L}$ de DNA (10 a 100ng) e $16,5 \mu \mathrm{L}$ de água ultrapura, para as reações com CgInt ou com CaInt2. As condições de amplificação foram: um ciclo de desnaturação inicial por $2 \mathrm{~min}$ a $94^{\circ} \mathrm{C}$; 30 ciclos de desnaturação por $1 \mathrm{~min}$ a $94^{\circ} \mathrm{C}$; anelamento por $1 \mathrm{~min}$ a $51^{\circ} \mathrm{C}$ e extensão por $1 \mathrm{~min}$ a $72^{\circ} \mathrm{C}$. Após a amplificação, os produtos foram analisados em gel de agarose a $1,2 \%$, em tampão TBE (Tris-Borato, EDTA 0,5M pH 8,0) a 80V por $2 \mathrm{~h}$, corados com brometo de etídeo, visualizados sob luz ultravioleta e fotografados. 
Tabela 1 - Origem dos isolados de Colletotrichum coletados em brácteas de inflorescências de plantas ornamentais tropicais.

\begin{tabular}{|c|c|c|c|}
\hline \multirow{2}{*}{ Isolado } & \multirow[b]{2}{*}{ Hospedeira } & \multirow[b]{2}{*}{ Município } & \multirow[b]{2}{*}{ Estado } \\
\hline & & & \\
\hline $\mathrm{Cg} 1$ & Heliconia dimitri & Alhandra & Paraíba \\
\hline $\mathrm{Cg} 2$ & Heliconia chartacea & Alhandra & Paraíba \\
\hline $\operatorname{Cg} 3$ & Heliconia psitacorum & Alhandra & Paraíba \\
\hline $\operatorname{Cg} 4$ & Anthurium andraeanum & Guaiuba & Ceará \\
\hline $\operatorname{Cg} 5$ & Heliconia bihai & Guaiuba & Ceará \\
\hline $\operatorname{Cg} 6$ & Anthurium andraeanum & Fortaleza & Ceará \\
\hline $\operatorname{Cg} 7$ & Etlingera elatior & Fortaleza & Ceará \\
\hline $\operatorname{Cg} 8$ & Anthurium andraeanum & Guaramiranga & Ceará \\
\hline $\operatorname{Cg} 9$ & Anthurium andraeanum & Guaramiranga & Ceará \\
\hline Cg 10 & Etlingera elatior & Guaramiranga & Ceará \\
\hline Cg 12 & Heliconia chartacea & Primavera & Pernambuco \\
\hline $\operatorname{Cg} 14$ & Etlingera elatior & Abreu e Lima & Pernambuco \\
\hline Cg 15 & Etlingera elatior & Ribeirão & Pernambuco \\
\hline Cg 17 & Etlingera elatior & Ribeirão & Pernambuco \\
\hline Cg 18 & Heliconia bihai & Ribeirão & Pernambuco \\
\hline Cg 19 & Heliconia chartacea & Ribeirão & Pernambuco \\
\hline Cg 20 & Etlingera elatior & Ribeirão & Pernambuco \\
\hline Cg 21 & Etlingera elatior & Ribeirão & Pernambuco \\
\hline Cg 22 & Anthurium andraeanum & Igarassu & Pernambuco \\
\hline C 23 & Anthurium andraeanum & Igarassu & Pernambuco \\
\hline Cg 25 & Heliconia bihai & Igarassu & Pernambuco \\
\hline Cg 26 & Heliconia bihai & Igarassu & Pernambuco \\
\hline Cg 27 & Heliconia rostrata & Aldeia & Pernambuco \\
\hline Cg 28 & Heliconia rostrata & Aldeia & Pernambuco \\
\hline Cg 29 & Anthurium andraeanum & Aldeia & Pernambuco \\
\hline Cg 30 & Anthurium andraeanum & Aldeia & Pernambuco \\
\hline Cg 31 & Etlingera elatior & Aldeia & Pernambuco \\
\hline Cg 33 & Heliconia rostrata & Paulista & Pernambuco \\
\hline Cg 34 & Anthurium andraeanum & Paulista & Pernambuco \\
\hline C 35 & Anthurium andraeanum & Paulista & Pernambuco \\
\hline Cg 36 & Etlingera elatior & Paulista & Pernambuco \\
\hline Cg 37 & Etlingera elatior & Paulista & Pernambuco \\
\hline Cg 38 & Etlingera elatior & São Lourenço & Pernambuco \\
\hline Cg 39 & Heliconia bihai & Paudalho & Pernambuco \\
\hline $\operatorname{Cg} 40$ & Etlingera elatior & Paudalho & Pernambuco \\
\hline
\end{tabular}

Cinco isolados de Colletotrichum (Cg1, Cg15, Cg29, Cg31 e Cg32) e o isolado de C. acutatum utilizado como controle foram selecionados para o sequenciamento da região ITS2 do DNA ribossomal, com base nas diferenças de hospedeiro e/ou origem geográfica. A região ITS2 foi amplificada por PCR, utilizando o oligonucleotídeo ITS4, juntamente com CgInt (C. gloeosporioides) ou CaInt2 (C. acutatum), como previamente descrito. Os produtos de PCR foram purificados com o kit DNA and Gel Band Purification (GE Healthcare) e diretamente sequenciados em sequenciador automático de DNA (Applied Biosystems). As sequências de nucleotídeos foram analisadas por BLASTn, para confirmação da identidade dos isolados.
Para análise de PCR com oligonucleotídeos arbitrários (AP-PCR), foram utilizados três oligonucleotídeos derivados de marcadores microssatélites: (GACAC), (GACA) $)_{3}$ e (CAG) $)_{5}$. As PCRs foram realizadas em volume total de $20 \mu \mathrm{L}$, contendo $2 \mu \mathrm{L}$ de tampão $10 \mathrm{X}$ (KCl 100mM; Tris- $\mathrm{HCl}$ $100 \mathrm{mM}$ pH 9,0; Triton-X 1\%), 1,5 $\mu \mathrm{L}$ de $\mathrm{MgCl}_{2} 25 \mathrm{mM}$, 2,0 $\mu \mathrm{L}$ de dNTPs $2,5 \mathrm{mM}, 2 \mu \mathrm{L}$ do oligonucleotídeo correspondente, $1 \mathrm{U}$ da DNA Taq Polimerase, $1 \mu \mathrm{L}$ de DNA (10 a 100ng) e $10,5 \mu \mathrm{L}$ de água ultrapura. As condições de amplificação foram as descritas por FREEMAN \& SHABI (1996). 
Os produtos das amplificações foram tratados como descrito anteriormente. Foi construída uma matriz binária com base na presença ou ausência de bandas. A matriz foi analisada para similaridade de bandas usando o método de agrupamento UPGMA (unweighted pair-group method with arithmetic average) e calculada com o coeficiente de NEI \& LI, utilizando o programa Treecon v.1.3b (VAN DE PEER \& DE WACHTER, 1994).

\section{RESULTADOS E DISCUSSÃO}

Todos os isolados produziram conídios hialinos, unicelulares, retos e cilíndricos. Os valores médios obtidos por meio da medida do comprimento dos conídios variaram de 10,4 a 17,6 $\mu$ m e da largura de 3,2 a 4,7 $\mu \mathrm{m}$ (Tabela 2). A maioria dos isolados produziu apressórios de coloração marrom-escuro e formato variável, clavados ou irregulares. O comprimento médio

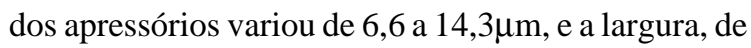

Tabela 2 - Caracterização morfológica de isolados de Colletotrichum coletados em brácteas de inflorescências de plantas ornamentais tropicais.

\begin{tabular}{|c|c|c|c|c|}
\hline \multirow{3}{*}{ Isolado } & \multicolumn{4}{|c|}{----------------------------------------------------Morfologia------------------------------------------------- } \\
\hline & \multicolumn{2}{|c|}{ Conídio $(\mu \mathrm{m})$} & \multicolumn{2}{|c|}{ Apressório $(\mu \mathrm{m})$} \\
\hline & Comprimento & Largura & Comprimento & Largura \\
\hline $\operatorname{Cg} 1$ & $14,5(10-22,5)$ & $3,2(2,5-5,0)$ & $12,7(6,2-25,0)$ & $3,2(2,5-5,0)$ \\
\hline $\operatorname{Cg} 2$ & $10,4(7,5-13,7)$ & $3,5(2,5-5,0)$ & $11,0(7,5-17,5)$ & $5,7(5,0-7,5)$ \\
\hline Cg 3 & $13,7(10-22,5)$ & $3,8(3,7-5,0)$ & $7,0(5,0-10,0)$ & $6,2(5,0-7,5)$ \\
\hline $\operatorname{Cg} 4$ & $16,7(11-26,5)$ & $3,6(2,5-5,0)$ & $10,2(7,5-15,0)$ & $6,5(3,7-8,7)$ \\
\hline Cg 5 & $11,8(7,5-17,5)$ & $3,4(2,5-6,5)$ & $10,9(8,7-16,2)$ & $6,9(6,5-10)$ \\
\hline $\operatorname{Cg} 6$ & $17,0(10-36,2)$ & $4,2(2,5-6,2)$ & $11,1(6,2-17,5)$ & $7,2(5,0-15)$ \\
\hline $\operatorname{Cg} 7$ & $11,7(8,7-15,0)$ & $4,3(2,5-5,0)$ & $9,1(6,2-13,7)$ & $5,8(5,0-7,5)$ \\
\hline $\mathrm{Cg} 8$ & $11,3(8,7-13,7)$ & $3,8(2,5-5,0)$ & $-{ }^{1}$ & - \\
\hline $\operatorname{Cg} 9$ & $12,3(6,2-21,2)$ & $3,5(2,5-6,2)$ & $8,9(6,2-12,5)$ & $5,9(3,7-8,7)$ \\
\hline $\operatorname{Cg} 10$ & $14,6(11,2-18)$ & $3,7(2,5-5,0)$ & $14,3(7,5-18,7)$ & $5,5(5-6,2)$ \\
\hline Cg 12 & $14,2(7,5-25,0)$ & $3,7(2,5-5,0)$ & $10,1(7,5-13,7)$ & $6,3(5,0-8,7)$ \\
\hline $\operatorname{Cg} 14$ & $11,7(8,7-18,7)$ & $4,5(2,5-5,0)$ & $8,5(6,2-13,7)$ & $5,1(3,7-6,2)$ \\
\hline Cg 15 & $10,5(7,5-15,0)$ & $3,5(2,5-5,0)$ & $7,5(6,2-11,2)$ & $5,3(3,7-6,2)$ \\
\hline Cg 17 & $15,5(11,2-31)$ & $4,3(2,5-6,2)$ & $12,5(6,2-18,7)$ & $7,1(5-11,2)$ \\
\hline Cg 18 & $14,4(8,7-22,5)$ & $3,6(2,5-5,0)$ & $8,9(6,2-13,7)$ & $5,8(5,0-7,5)$ \\
\hline Cg 19 & $13,7(8,7-23,7)$ & $3,3(2,5-5,0)$ & - & - \\
\hline Cg 20 & $13,8(10-24,0)$ & $3,0(2,5-3,7)$ & $7,2(5,0-10,0)$ & $5,2(3,7-7,5)$ \\
\hline $\operatorname{Cg} 21$ & $12,2(7,5-16,5)$ & $3,4(2,5-5,0)$ & $6,6(5,0-10,0)$ & $5,5(3,7-7,5)$ \\
\hline Cg 22 & $15,5(7,5-23,7)$ & $4,0(2,5-5,0)$ & $9,8(6,2-12,5)$ & $6,0(3,7-8,7)$ \\
\hline C 23 & $17,1(13,7-32)$ & $4,7(3,7-5,0)$ & - & - \\
\hline Cg 25 & $14,3(10-23,7)$ & $3,8(2,5-5,0)$ & $7,4(5,0-11,2)$ & $6,0(5,0-7,5)$ \\
\hline Cg 26 & $14,2(8,7-25,0)$ & $4,2(3,7-6,2)$ & $8,6(6,2-13,7)$ & $5,9(3,7-7,5)$ \\
\hline Cg 27 & $12,8(8,7-21,2)$ & $3,9(2,5-5,0)$ & $11,8(8,7-17,5)$ & $6,7(6,2-8,7)$ \\
\hline Cg 28 & $17,6(8,7-33,7)$ & $3,4(2,5-5,0)$ & $9,2(6,2-13,7)$ & $6,1(3,7-8,7)$ \\
\hline Cg 29 & $13,7(8,7-22,5)$ & $4,4(2,5-6,2)$ & $9,9(7,5-13,7)$ & $6,7(5-11,2)$ \\
\hline Cg 30 & $12,3(7,5-18,7)$ & $3,7(2,5-5,0)$ & $9,5(7,5-12,5)$ & $6,2(5,0-8,7)$ \\
\hline Cg 31 & $15,9(12-23,7)$ & $4,3(3,7-5,0)$ & $15,6(12-22,5)$ & $6,1(5,0-7,1)$ \\
\hline Cg 33 & $10,7(7,5-16,2)$ & $2,8(2,5-3,7)$ & $11,1(7,5-16,2)$ & $6,0(5,0-7,5)$ \\
\hline $\mathrm{Cg} 34$ & $12,7(7,5-20,0)$ & $3,5(2,5-6,2)$ & $10,2(6,2-17,5)$ & $5,7(5,0-6,2)$ \\
\hline C 35 & $15,0(11-31,2)$ & $4,7(3,7-6,2)$ & $12,5(6,2-21,2)$ & $7,9(3,7-15)$ \\
\hline Cg 36 & $13,2(8,7-18,7)$ & $3,6(2,5-3,7)$ & $9,6(7,5-16,2)$ & $5,6(5,0-7,5)$ \\
\hline Cg 37 & $12(7,5-17,5)$ & $3,5(2,5-6,2)$ & $9,2(6,2-12,5)$ & $5,1(3,7-6,2)$ \\
\hline $\mathrm{Cg} 38$ & $12,3(7,5-18,6)$ & $3,7(2,5-5,0)$ & $9,5(7,5-12,5)$ & $6,2(5,0-8,7)$ \\
\hline Cg 39 & $16,7(10-32,5)$ & $4,3(3,7-6,2)$ & $8,9(5,0-12,5)$ & $6,1(5,0-7,5)$ \\
\hline $\operatorname{Cg} 40$ & $11,8(3,7-17,5)$ & $3,5(2,5-6,2)$ & $9,0(6,2-15,0)$ & $6,3(5,0-8,7)$ \\
\hline
\end{tabular}

${ }^{1}$ Não foi produzido.

Ciência Rural, v.39, n.6, set, 2009. 
3,2 a 7,9 9 m (Tabela 2). Os isolados Cg 8, Cg 19 e C 23 não produziram apressórios. A coloração das colônias, em meio de cultura BDA, variou de branco a cinzaescuro, com predominância de branco e brancoacinzentado. As medidas de tamanho de conídios e apressórios e a coloração de colônia de todos os isolados analisados estão de acordo com o descrito para C. gloeosporioides por SUTTON (1980). Esse resultado está de acordo com o observado em trabalhos de ocorrência da antracnose em algumas espécies ornamentais tropicais (PITTA et al., 1990; LINS \& COELHO, 2004; BARGUIL et al., 2005; ALMEIDA et al., 2006).

Em nenhum isolado analisado houve a amplificação do fragmento de 490pb correspondente à C. acutatum, com a utilização de CaInt2 e ITS4, apenas para o isolado proveniente de A. occidentale. A utilização do oligonucleotídeo CgInt, específico para C. gloeosporioides, usado em conjunto com o oligonucleotídeo ITS4, resultou na produção de um fragmento de $450 \mathrm{pb}$ correspondente à espécie $\boldsymbol{C}$. gloeosporioides (Figura 1). Não houve amplificação para o isolado controle identificado previamente como C. acutatum. Nas análises realizadas, a banda de 450pb gerada para o isolado Cg 6 apresentou fraca intensidade, enquanto que o DNA dos isolados C 23 e C 35 não foi amplificado por nenhum dos oligonucleotídeos específicos testados (resultados não mostrados).

A utilização de PCR com oligonucleotídeos espécie-específicos capazes de amplificar uma região do DNA nuclear ribossomal foi útil na identificação de C. gloeosporioides como o agente causal da antracnose observada em inflorescências de plantas ornamentais tropicais, sendo identificados por métodos moleculares pela primeira vez neste trabalho. Embora a banda de 450pb específica para $C$. gloeosporioides não tenha sido amplificada para os isolados C 23 e C 35 , estes foram identificados por meio das características morfológicas como pertencentes ao gênero Colletotrichum. A ausência de banda após a amplificação por PCR utilizando o oligonucleotídeo CgInt já foi relatada para isolados de Colletotrichum provenientes de maracujá (AFANADOR-KAFURI et al., 2003) e mangueira (SERRA, 2006). Entretanto, apesar desses isolados terem sido identificados pelas características morfológicas como C.gloeosporioides, AFANADOR-KAFURI et al. (2003) os consideraram pertencentes a uma espécie de Colletotrichum não identificada.

A análise de comparação de sequências da região ITS2 por BLASTn confirmou que os isolados Cg 1, Cg 15, Cg 29, Cg 31 e Cg 32 pertencem à espécie C. gloeosporioides, e o isolado controle pertence à espécie $\boldsymbol{C}$. acutatum. Esse resultado corrobora aquele obtido pela amplificação específica da região ITS dos isolados e também pela morfologia. Os valores de $e$ para os isolados Cg 1, Cg 15, Cg 29, Cg 31, Cg 32 e C. acutatum foram respectivamente: $1 e-78,2 e-75,1 e-71$, 1e-72, $2 e-74$ e $4 e-78$. As sequências de nucleotídios foram depositadas no GenBank sob os números de acesso FJ465515, FJ465516, FJ465517, FJ465518, FJ465519 e FJ 465520 para os isolados Cg 1, Cg 15, Cg 29, Cg 31, Cg 32 e C. acutatum, respectivamente.

A caracterização molecular dos isolados de Colletotrichum foi realizada com três oligonucleotídeos arbitrários. Trinta loci AP-PCR foram identificados nos isolados estudados, independentemente da intensidade, estando no intervalo de 400 a 1600pb. Excluindo-se as bandas de intensidade fraca, foram analisadas 24 bandas.

O oligonucleotídeo (GACAC) ${ }_{3}$ foi aquele que gerou menor número de bandas polimórficas. $\mathrm{O}$ primeiro agrupamento compreendeu 54,28\% dos isolados com o mesmo perfil de bandas [Cg 1, Cg 3, Cg 4, Cg 5, Cg 8, Cg 18, Cg 19, Cg 20, Cg 21, Cg 22, Cg 25, Cg 26, Cg 27, Cg 28, Cg 29, Cg 30, Cg 34, Cg 36 e Cg 40], o segundo padrão foi formado por $20 \%$ dos isolados

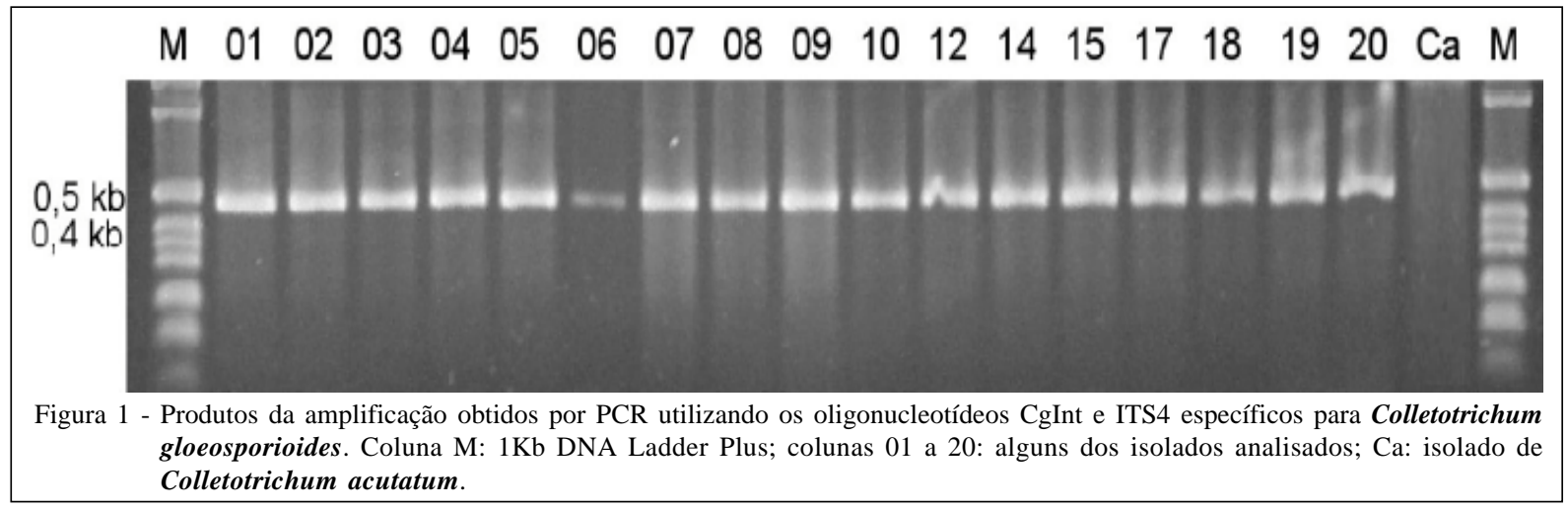

Ciência Rural, v.39, n.6, set, 2009. 
[Cg 2, Cg 9, Cg, 14, Cg 15, Cg 37, Cg 38 e Cg 39], enquanto que os isolados [Cg 6, C 23 e C 35] formaram um terceiro agrupamento e os quatro isolados restantes Cg 7, Cg 10, Cg 12 e Cg 17 apresentaram padrões distintos (Figura 2A). O oligonucleotídeo (GACA) subdividiu os isolados em nove grupos distintos, sendo o primeiro formado por $25,71 \%$ dos isolados [Cg 2, $\mathrm{Cg}$ 7, Cg 9, Cg 14, Cg 15, Cg 33, Cg 34, Cg 37 e Cg 38] e o segundo, por 20\% dos isolados [Cg 5, Cg 18, Cg 20, Cg 21, Cg 30, Cg 36 e Cg 40]. Os demais agrupamentos foram [Cg 1, Cg 22, Cg 26 e Cg 27], [Cg 12, Cg 25, Cg 39], [Cg 6, C 23 e Cg 35], [Cg 10, Cg 17 e Cg 31], [Cg 8, Cg 28 e Cg 29], [Cg 3 e Cg 19] e [Cg 4] (Figura 2B). Já o oligonucleotídeo (CAG), propiciou o maior número de bandas polimórficas, em que quase metade dos isolados apresentou perfis únicos de banda (Figura 2C e 2D).

Análises de AP-PCR foram utilizadas na diferenciação de isolados de Colletotrichum de abacate e amêndoas (FREEMAN et al., 1996) e em oliveira (TALHINHAS et al., 2005), dentre outras hospedeiras. Entretanto, não se tem conhecimento do uso do marcador AP-PCR no estudo da variabilidade de Colletotrichum sp. provenientes de plantas ornamentais.

A análise de agrupamento revelou a existência de três grupos (I, II e III), os quais se repetiram quando todos os loci em conjunto foram analisados, correspondendo aos agrupamentos obtidos com cada oligonucleotídeo em separado (dados não mostrados). Independentemente de suas origens geográficas ou de hospedeiro, os isolados $\mathrm{Cg}$ 14, Cg 37 e Cg 38 e os isolados Cg 36 e Cg 40 apresentaram o mesmo perfil de bandas para os três oligonucleotídeos testados (Figura 2), sendo arranjados no grupo I (Figura 3). No grupo II, os isolados Cg 26 e Cg 27 apresentaram perfil similar de bandas, sendo o mesmo comportamento observado para os isolados $\mathrm{Cg}$ 6, C 23 e C 35, que compõem o grupo III (Figura 3).

Poderia se esperar que houvesse algum tipo de separação entre os isolados amostrados no presente estudo, ou por origem geográfica ou por hospedeiro de origem. Isolados coletados em diferentes hospedeiros apresentaram perfis de bandas semelhantes, sendo distribuídos em um mesmo grupo (Figura 3). Da mesma forma, isolados de origens geográficas distintas também apresentaram o mesmo padrão de bandas na AP-PCR. Isolados provenientes dos Municípios de Aldeia e Paulista, no Estado de Pernambuco, apresentaram perfis de bandas similares a isolados coletados nos Municípios de Fortaleza e Guaramiranga, no Estado do Ceará, distantes cerca de $800 \mathrm{~km}$. A variabilidade aqui observada pode estar relacionada com a inespecificidade dos isolados, que também foi encontrada em isolados coletados em maracujás cultivados na Colômbia (AFANADORKAFURI et al., 2003). É possível também que isolados com padrões similares de bandas se comportem de forma diferente na patogenicidade (XIAO et al., 2004).

A análise genética da população pode contribuir para o entendimento do potencial evolutivo de C. gloeosporioides, possibilitando o desenvolvimento de estratégias de manejo de controle apropriadas. É sabido que $\boldsymbol{C}$. gloeosporioides é um fungo de limitada dispersão a longas distâncias e que o material vegetal infectado é a principal via de dispersão. Portanto, infere-se que a troca de material
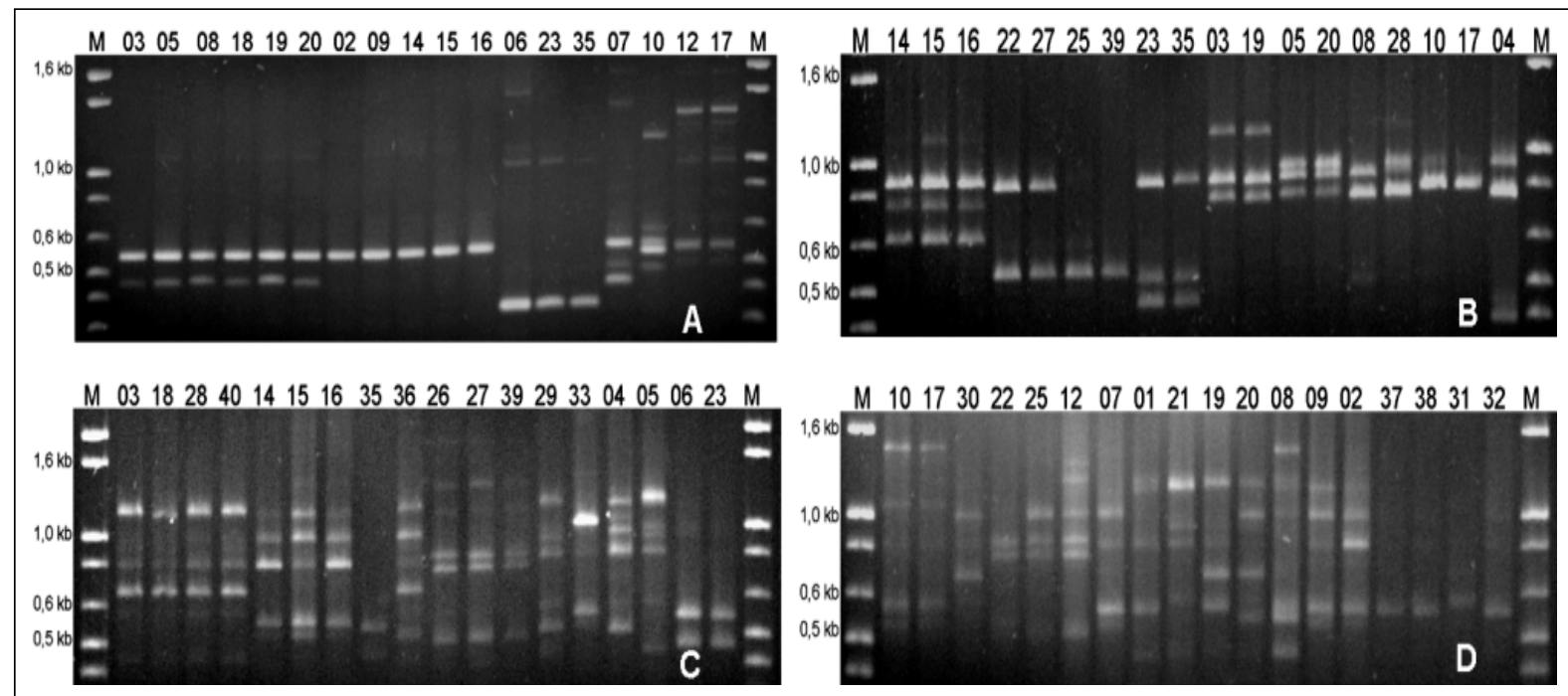

Figura 2 - Produtos da amplificação obtidos por análise de AP-PCR utilizando os oligonucleotídeos arbitrários (GACAC) 3 (A), $(\mathrm{GACA})_{4}(\mathrm{~B})$ e $(\mathrm{CAG})_{5}$ (C e D). Linha M: marcador de tamanho molecular (1Kb DNA Ladder Plus).

Ciência Rural, v.39, n.6, set, 2009. 


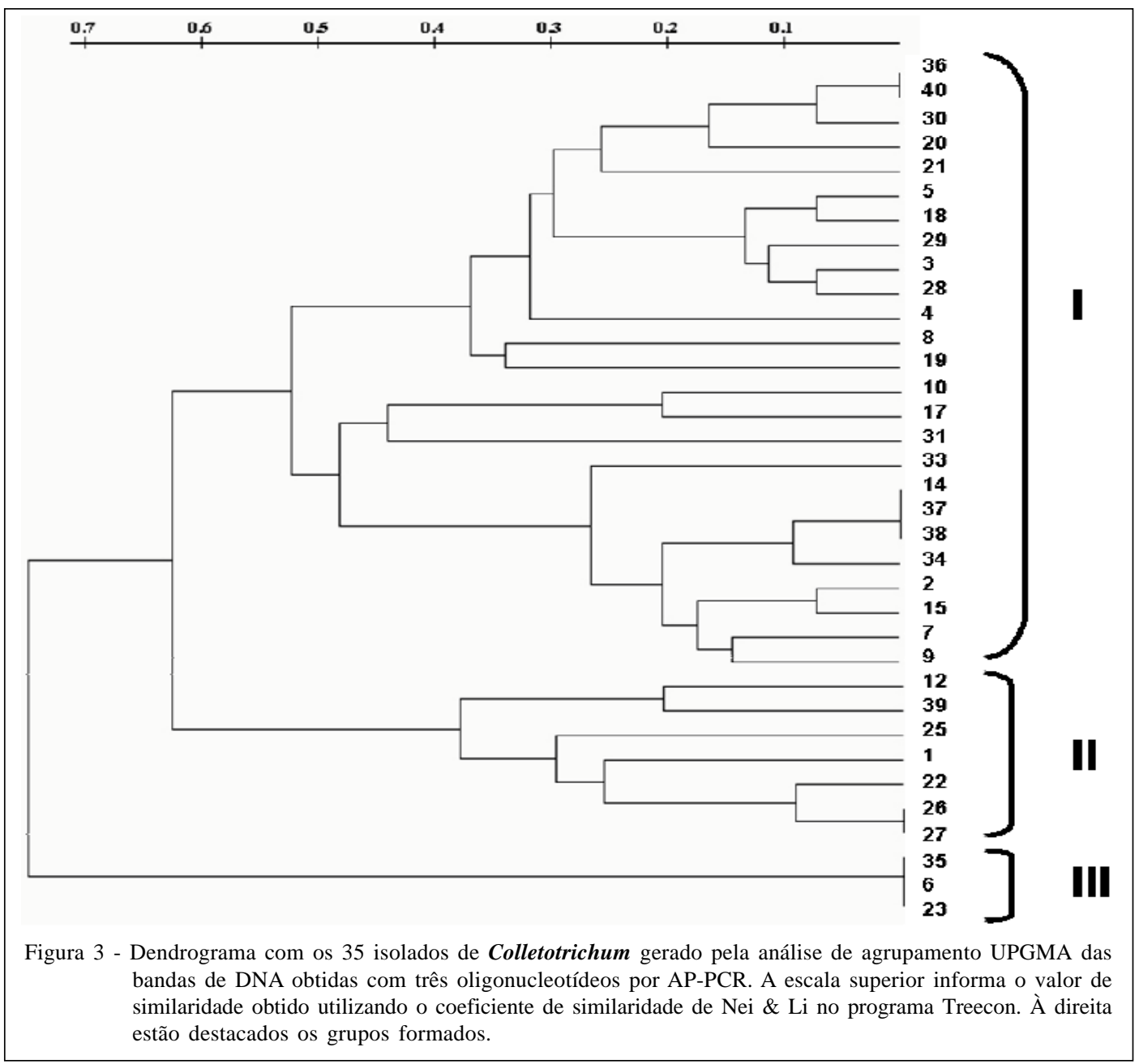

vegetal infectado dentre e entre Estados possa ser responsável pela disseminação de isolados desse patógeno. O provável movimento de indivíduos entre regiões contribui para a não correlação entre distância genética e geográfica, reforçando a probabilidade de fluxo do patógeno via material vegetal infectado, em que o mesmo padrão de formação de bandas pôde ser encontrado em isolados provenientes de municípios distantes.

\section{AGRADECIMENTOS}

Os autores agradecem ao Conselho Nacional de Desenvolvimento Científico e Tecnológico (CNPq) e a Coordenação de Aperfeiçoamento de Pessoal de Nível Superiror (CAPES), pelas bolsas concedidas aos estudantes de doutorado. Os autores também agradecem ao professor Dr. Francisco Murilo Zerbini, da Universidade Federal de Viçosa, por ter cedido o laboratório para a caracterização molecular dos isolados.

\section{REFERÊNCIAS}

AFANADOR-KAFURI L. et al. Characterization of Colletotrichum isolates from tamarillo, passiflora, and mango in Colombia and identification of a unique species from the genus. Phytopathology, St. Paul, v. 93, p. 579-587, 2003. Disponível em: <http://apsjournals.apsnet.org/doi/pdfplus/ 10.1094/PHYTO .2003.93.5.579>. Acesso em: 10 jul. 2008. Doi: 10.1094/PHYTO.2003.93.5.579.

ALMEIDA, G.T. et al. Antracnose causada por Colletotrichum gloeosporioides em inflorescências de Calathea burlemax cv. Green no Brasil. Fitopatologia Brasileira, Brasília, v.31, S326, 2006.

BARGUIL, B.M. et al. Ocorrência de Colletotrichum gloeosporioides em Heliconia chartacea cv. Sex Pink. Fitopatologia Brasileira, Brasília, v.30, p.S136, 2005.

FERREIRA, M.E.; GRATTAPAGLIA, D. Introdução ao uso de marcadores moleculares em análise genética. Brasília, BR: Empresa Brasileira de Pesquisa Agropecuária, 1998. 220p. 
FREEMAN, S. et al. Characterization of Colletotrichum gloeosporioides isolates from avocado and almond fruits with molecular and pathogenicity tests. Applied and Environmental Microbiology, Washington, v.62, p.10141020, 1996.

FREEMAN, S.; SHABI, E. Cross-infection of subtropical and temperate fruits by Colletotrichum species from various hosts. Physiological and Molecular Plant Pathology, Amsterdan, v.49, p.395-404, 1996. Disponível em: <http:// www.sciencedirect.com/science?ob=ArticleURL\&udi=B6WPC$45 \mathrm{~N} 43 \mathrm{VB}-5 \&$ user $=686348 \& \mathrm{rdoc}=1 \& \mathrm{fmt}=\&$ orig $=$ search\&sort $=\mathrm{d} \&$ view $=\mathrm{c} \&$ acct $=\mathrm{C} 000037259 \&$ version $=$ 1\&urlVersion=0\&userid=686348\&md5=92d25elfc7e3f9b680008ce49fe93e78> . Acesso em: 25 mar. 2008. Doi: 10.1006/pmpp.1996.0062.

LINS, S.R.O.; COELHO, R.S.B. Ocorrência de doenças em plantas ornamentais tropicais no Estado de Pernambuco. Fitopatologia Brasileira, Brasília, v.29, p.332-335, 2004. Disponível em: < http://www.scielo.br/pdf/fb/v29n3/20374.pdf>. Acesso em: 28 nov. 2007. Doi: 10.1590/S010041582004000300019 .

LOGES, V. et al. Colheita, pós-colheita e embalagem de flores tropicais em Pernambuco. Horticultura Brasileira, Brasília, v.23, p.699-702, 2005. Disponível em: < http://www.scielo.br/ pdf/hb/ v23n3/a01v23n3.pdf >. Acesso em: 22 fev. 2008. Doi: 10.1590/S0102-05362005000300001.

MENEZES, M.; ASSIS, S.M.P. Guia prático para fungos fitopatogênicos. Recife: Universidade Federal Rural de Pernambuco, 2004. $183 \mathrm{p}$.

PERES, N.A.R. et al. Identification and characterization of Colletotrichum spp. affecting fruit after harvest in Brazil. Journal of Phytopathology, Berlin, v.150, p.128-134, 2002. Disponível em: <http://www3.interscience.wiley.com/cgi-bin/ fulltext/120844717/HTMLSTART>. Acesso em: 25 mar. 2008. Doi: 10.1046/j.1439-0434.2002.00732.x.

PITTA, G.P.B. et al. Doenças das plantas ornamentais. São Paulo, BR: Instituto Brasileiro do Livro Científico, 1990. $174 \mathrm{p}$.

SERRA, I.M.R.S. Colletotrichum gloeosporioides agente de antracnose em cajueiro e mangueira: eficiência de métodos morfofisiológicos e moleculares na diferenciação e identificação específica dos isolados.
2006. 183f. Tese (Doutorado em Fitopatologia) - Curso de pós-graduação em Fitopatologia, Universidade Federal Rural de Pernambuco.

SICARD, D. et al. Genetic diversity and pathogenic variation of Colletotrichum lindemuthianum in the three centers of diversity of its host, Phaseolus vulgaris. Phytopathology, St. Paul, v.87, p.807-813, 1997. Disponível em: <http:// apsjournals.apsnet.org/doi/pdfplus/10.1094/ PHYTO.1997.87.8.807>. Acesso em: 10 jun.2008. Doi: 10.1094/PHYTO.1997.87.8.807.

SUTTON, B.C. The Coelomycetes. Kew: Commonwealth Mycological Institute, 1980. 696p.

TALHINHAS, P. et al. Genetic and morphological characterization of Colletotrichum acutatum causing anthracnose of Lupins. Phytopathology, St. Paul, v.92, p.986966, 2002. Disponível em: < http://apsjournals.apsnet.org/ doi/pdfplus/10.1094/PHYTO.2002.92.9.986> Acesso em: 25 abr. 2008. Doi: 10.1094/PHYTO.2002.92.9.986.

TALHINHAS, P. et al. Molecular and phenotypic analyses reveal association of diverse Colletotrichum acutatum groups and a low level of C. gloeosporioides with olive anthracnose. Applied and Environmental Microbiology, Washington, v.71, p.29872998, 2005. Disponível em: < http://aem.asm.org/cgi/reprint/ 71/6/2987? maxtoshow $=\&$ HITS $=10$ \&hits $=10 \&$ RESULTFO RMAT=\&author1 $=$ talhinhas\&searchid $=1 \&$ FIRSTINDEX $=0$ \&fdate $=1$ / $1 / 2004 \&$ tdate $=3 / 31 / 2006 \&$ resourcetype $=$ HWCIT $>$. Acesso em: 30 abr. 2008. Doi: 10.1128/AEM.71.6.2987-2998.2005.

VAN DE PEER, Y.; De WACHTER, R. TREECON for windows: a software package for the construction and drawing of evolutionary trees for the Microsoft Windows environment. Computer Applications in the Biosciences, v.10, p.569570, 1994.

WARUMBY, J.F. et al. Principais doenças e pragas em flores tropicais no Estado de Pernambuco. Recife: Sebrae, 2004. 98p.

XIAO, C.L. et al. Genetic and pathogenic analyses of Colletotrichum gloeosporioides isolates from strawberry and noncultivated hosts. Phytopathology, St. Paul, v.94, p.446453, 2004. Disponível em: <http://apsjournals.apsnet.org/doi/ pdfplus/10.1094/PHYTO.2004.94.5.446>. Acesso em: 26 jan. 2008. Doi: 10.1094/PHYTO.2004.94.5.446. 